\title{
$1 \quad$ Neuronal circuitry for stimulus selection in the visual system
}

3

4 António M. Fernandes ${ }^{1}$, Johannes Larsch ${ }^{1}$, Joseph C. Donovan ${ }^{1}$, Thomas O.

5 Helmbrecht ${ }^{1}$, Duncan Mearns ${ }^{1}$, Yvonne Kölsch ${ }^{1}$, Marco Dal Maschio ${ }^{1,2}$, Herwig Baier ${ }^{1 *}$

6

$7{ }^{1}$ Department Genes-Circuits-Behavior, Max Planck Institute of Neurobiology, 82152,

8 Martinsried, Germany

9

102 Department of Biomedical Sciences, University of Padua, Padua Neuroscience

11 Center, University of Padua via Ugo Bassi 58B, 35131 Padova, Italy

12

13 *For correspondence: hbaier@neuro.mpg.de 
Visual objects naturally compete for the brain's attention, and selecting just one of them for a behavioural response is often crucial for the animal's survival ${ }^{1}$. The neural correlate of such stimulus prioritisation might take the form of a saliency map by which responses to one target are enhanced relative to distractors in other parts of the visual field ${ }^{2}$. Single-cell responses consistent with this type of computation have been observed in the tectum of primates, birds, turtles and lamprey ${ }^{2-7}$. However, the exact circuit implementation has remained unclear. Here we investigated the underlying neuronal mechanism presenting larval zebrafish with two simultaneous looming stimuli, each of which was able to trigger directed escapes on their own. Behaviour tracking revealed that the fish respond to these competing stimuli predominantly with a winner-take-all strategy. Using brain-wide functional recordings, we discovered neurons in the tectum whose responses to the target stimulus were non-linearly modulated by the saliency of the distractor. When the two stimuli were presented monocularly in different positions of the visual field, stimulus selection was already apparent in the activity of retinal ganglion cell axons, a likely consequence of antagonistic mechanisms operating outside the classical receptive field ${ }^{8,9}$. When the two stimuli were presented binocularly, i.e., on opposite sides of the fish, our analysis indicates that a loop involving excitatory and inhibitory neurons in the nucleus isthmi (NI) and the tectum weighed stimulus saliencies across hemispheres. Consistent with focal enhancement and global suppression, glutamatergic NI cells branch locally in the tectum, whereas GABAergic NI cells project broadly across both tectal hemispheres. Moreover, holographic optogenetic stimulation confirmed that glutamatergic NI neurons can modulate visual responses in the tectum. Together, our study shows, for the first time, context-dependent contributions of retinotectal and isthmotectal circuits to the computation of the visual saliency map, a prerequisite for stimulus-driven, bottom-up attention. 
Dark, looming stimuli are strongly aversive stimuli for zebrafish larvae ${ }^{10,11}$ and other animals ${ }^{12,13}$, probably mimicking an approaching predator or an object on a collision course. In our setup, single looming disks presented from below and on one side of a free-swimming animal were highly effective in driving an escape response to the contralateral side (Fig. 1a-c, Extended Data Fig. 1i, j). Depending on the location and the strength of the stimulus, fish larvae adjust direction and magnitude of their response. We identified loom expansion rate and contrast as key factors that modulate escape probability (Extended Data Fig. 1a-e, see also ${ }^{14}$ ). We asked how zebrafish respond to two looming stimuli presented simultaneously (Fig. 1d). We reasoned that fish may either "select" one of the two stimuli for response and suppress a response to the other stimulus (winner-take-all hypothesis); alternatively, fish might integrate both stimuli, triggering an escape response in a direction along the mean vector of responses to either stimulus presented alone (averaging hypothesis) ${ }^{15-18}$.

When we presented two stimuli of equal strength, appearing on either side of the fish, we observed a bimodal distribution of escape trajectories. Larvae consistently escaped in a sideways direction away from one, apparently randomly chosen disk (Fig. 1d, Extended Data Fig. 1g). Modulating the expansion rate of one stimulus (e.g. slower expansion rate) biased the combined responses away from the stronger stimulus (Fig. 1e-f, Extended Data Fig. 1f-o). While this result argues in favour of a winner-take-all mechanism, a smaller, but significant fraction of responses pointed toward an intermediate direction, consistent with an averaging strategy. To estimate the relative contribution of each strategy, we fit a biased-mixture model implementing predictions from both hypotheses (Fig $1 \mathrm{~g}$ ). For equal stimuli (bias $=0.5$ ), we found that a mix of winner-take-all ( $80 \%$ of responses) and averaging (20\% of responses) best explained the data (Fig 1h, j and Extended Data Fig. 1k, m). For unequal stimuli, we additionally fit the bias term (Fig. 1i). This revealed that fish selected the stronger stimulus $70 \%$ of the times, (bias term $=0.7)($ Fig 1i-k, Extended Data Fig. 1I, n)).

We next asked if the winner-take-all behavioural strategy extended to a situation where two looming stimuli were displayed to the same eye in non-overlapping parts of the visual field (Extended Data Fig. 2). A single looming disk, positioned in the posterior visual field, triggered a forward escape, $\left(47^{\circ}+/-3.9\right.$ SEM), whereas an anteriorly located disk triggered a sideways escape (82.5 +/- 7.6 SEM) (Extended Data Fig. 2I). 
Both stimuli together triggered a distribution of escape angles that included the responses to single stimuli. The limited dynamic range of escape angles for the two stimuli precluded fitting our biased-mixture model. However, as with binocular stimulation, the faster of two monocular stimuli dominated escape direction such that its mean angle was indistinguishable from that triggered by the stimulus alone (Extended Data Fig. 2l). Thus, stimulus selection is also detectable with monocular stimuli.

Next we investigated the potential neural correlates of stimulus selection using brainwide calcium imaging (Fig. 2a, b). We first determined which regions responded reliably to looming stimuli (Extended Data Fig. 3a). As shown previously ${ }^{10,19}$, looming stimuli activated retinal ganglion cell (RGC) axons, the tectum, the pretectum and a thalamic area near retinal arborisation field AF4. We also found a responsive area at the midbrain-hindbrain boundary that we identified as the putative zebrafish homolog of the nucleus isthmi $(\mathrm{NI})^{20}$, a region that has previously been implicated in the generation of a visual 'saliency map' 3,6,21-23.

Competing ensembles of tectal neurons have been observed in the zebrafish tectum ${ }^{24}$. We hypothesised that we should find at least two response types to the competing looming response: (i) neurons whose activities scale with the strength of one stimulus and (ii) neurons whose activities are suppressed by the competing stimulus. We designed a protocol to find these two response types. We kept the expansion rate of one looming stimulus constant (S1), while systematically varying the velocity of the competitor stimulus (S2) (Fig. 2c). Presenting two competing stimuli to the same eye resulted in the suppression of activity in a subset of tectal cells (Fig. $2 d, f, h$, in magenta). The response of these cells to $\mathrm{S} 1$ was substantially reduced, when S2 was stronger or identical to S1 (Fig. 2f) but was high when S2 was weaker than S1. On the other hand, we found responses that scaled with increasing S2 speed (Fig. 2d, f, h, in green). These findings are consistent with stimulus competition by reciprocal inhibition ${ }^{25,26}$. Similar response profiles to looming stimuli have previously been called "switch-like" in the barn owl ${ }^{22}$. Remarkably, we observed switch-like responses already at the level of the RGC axons (Fig. 2d, e, g, Extended Data Fig. 3b-c). This suggests that monocular stimulus competition affects the activity of RGCs and may be inherited by tectal cells. In agreement with previous reports ${ }^{22,25}$, the switch transition for the 
112 population response is flexible and shifts systematically with the strength of the S1

113 stimulus (Fig 2i, Extended Data Fig. 3c, e). Tectal cells are more switch-like compared

114 to RGCs, suggesting that saliency computation is amplified in the tectum (correlation

115 coefficients, RGCs: $R=0.47$, Tectum: $R=0.72$, Fig. $2 \mathrm{i}$ ). To ask if the stimulus

116 competition extends to stimuli with different valence, we designed synthetic, prey-like

117 stimuli, which evoke hunting behavior ${ }^{27}$. Indeed, RGC axons and tectal responses

118 showed suppression and enhancement driven by a competing prey stimulus on the

119 same hemisphere (Extended Data Fig. 4a-c). Such a mechanism might facilitate

120 efficient target selection during hunting against a background of distractors.

122 The suppression observed in RGC terminals is likely the result of intraretinal

123 processing of competing stimuli by means of lateral inhibition ${ }^{28,29}$. To rule out that RGC

124 axon terminals receive feedback modulation within the tectum ${ }^{30}$, we ablated the tectal

125 cells and then imaged the RGC terminals in response to competing looming stimuli.

126 Switch-like responses of RGCs remained intact upon removal of tectal influences

127 (Extended Data Fig. 4d-h). Whereas responses in RGCs appeared unaffected, tectal

128 ablation led to severe impairments in responses to prey and looming stimuli as reported

129 previously ${ }^{10,27,31}$ (Extended Data Fig. 4i-4I). These results indicate that the formation

130 of saliency maps previously attributed to computations in higher-order visual areas

131 already begins in the inner retina.

133 Two stimuli presented to opposite sides of the fish (Fig. 3a), produced switch-like 134 suppression and enhancement of distinct populations of neurons, similar to same-eye 135 stimulation (Fig. 3c). We, therefore, predicted the existence of a circuit that compares 136 signals between the two eyes. Such dynamics were observed both in the tectum and 137 the $\mathrm{NI}$ across hemispheres (Fig. 3b-g). Using transmitter-specific lines ${ }^{32}$, we 138 determined that, as in other vertebrate species, cells in the $\mathrm{NI}$ either express 139 glutamatergic (vglut2a) or GABAergic (gad1b) markers in a mutually exclusive fashion 140 and express known marker genes for the isthmic region (e.g. Reelin) ${ }^{33}$ (Fig. 3h, 141 Extended Data Fig. 5). Some of the glutamatergic cells are also cholinergic. The 142 glutamatergic/cholinergic and GABAergic populations form two spatially segregated 143 nuclei across the hindbrain-midbrain boundary (Fig. 3h). Functional recordings 144 revealed that both $\mathrm{NI}$ populations display switch-like activity profiles; i. e., the response 145 to the target stimulus was suppressed by a competitor stimulus. However, only the 
146 glutamatergic neuronal activity scales with the strength of the competitor (Extended

147 Data Fig. 6).

149 To test whether there is a functional connection between the $\mathrm{NI}$ and tectum, we imaged

150 tectal and isthmic activity in response to a looming stimulus, while optogenetically

151 activating a subpopulation of excitatory $\mathrm{NI}$ neurons (Fig. 3i). We observed a strong

152 modulation of the stimulus-evoked activity in the contralateral $\mathrm{NI}$ and tectum;

153 responses were either enhanced or suppressed upon co-activation of glutamatergic NI

154 neurons (Fig. 3j, k, Extended Data Fig. 7). This suggests that photostimulation likely

155 activates different functional classes of neurons in the NI. As in adult frogs ${ }^{34}$, activation

156 of NI neurons alone (without a visual stimulus present) did not reliably lead to activation

157 of tectal cells (Extended Data Fig.7a-d).

159 Intertectal and tectobulbar projection neurons were recently described in larval

160 zebrafish ${ }^{35}$. Anatomical co-registration revealed that tectal axon terminals overlap with

161 dendritic arborisations of NI neurons on both sides of the brain (Fig. 4a, b, Extended

162 Data Fig. 8b-d). To search for isthmo-tectal connections, we stochastically labelled

163 single $\mathrm{NI}$ cells and traced their projections (Fig. 4c-f, Extended Data Fig. 8a-o). In

164 agreement with our optogenetic results, we found two classes of excitatory NI neurons

165 innervating both hemispheres along different pathways (Fig. 4c, d, Extended Data Fig.

$1668 \mathrm{k}-\mathrm{I})$. Glutamatergic axons arborise focally in either the ipsilateral or the contralateral

167 tectum. In contrast, GABAergic neurons arborise broadly in either one or both tecta

168 (Fig. 4e, f, Extended Data Fig. 8i-j, 8n). This anatomical architecture is in agreement

169 with our binocular competition results in the NI. In addition, it supports previous findings

170 showing interocular interactions between left and right $\mathrm{NI}^{36}$. Thresholding of the

171 difference in activity of left and right tectum has been proposed as a possible

172 mechanism to compare stimulus saliency in mammals ${ }^{37}$.

174 In conclusion, the topographical arrangement and transmitter identities of recurrent 175 connections in the isthmotectal loop support a saliency map mechanism, in which 176 representation of one stimulus is focally enhanced, while responses to stimuli 177 elsewhere are suppressed (Fig. 4g). Such a network could produce the observed 178 winner-take-all outcome of behavioural choice during stimulus competition 25,38,26. 179 Together, a feed-forward retinotectal and a modulatory isthmotectal recurrent circuit 
bioRxiv preprint doi: https://doi.org/10.1101/598383; this version posted April 4, 2019. The copyright holder for this preprint (which was not

certified by peer review) is the author/funder, who has granted bioRxiv a license to display the preprint in perpetuity. It is made available under aCC-BY-NC-ND 4.0 International license.

180 implement context-dependent target selection (Fig. $4 \mathrm{~g}$ ) and might form the basis of a 181 bottom-up attentional mechanism. 
bioRxiv preprint doi: https://doi.org/10.1101/598383; this version posted April 4, 2019. The copyright holder for this preprint (which was not

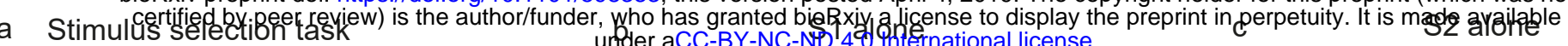
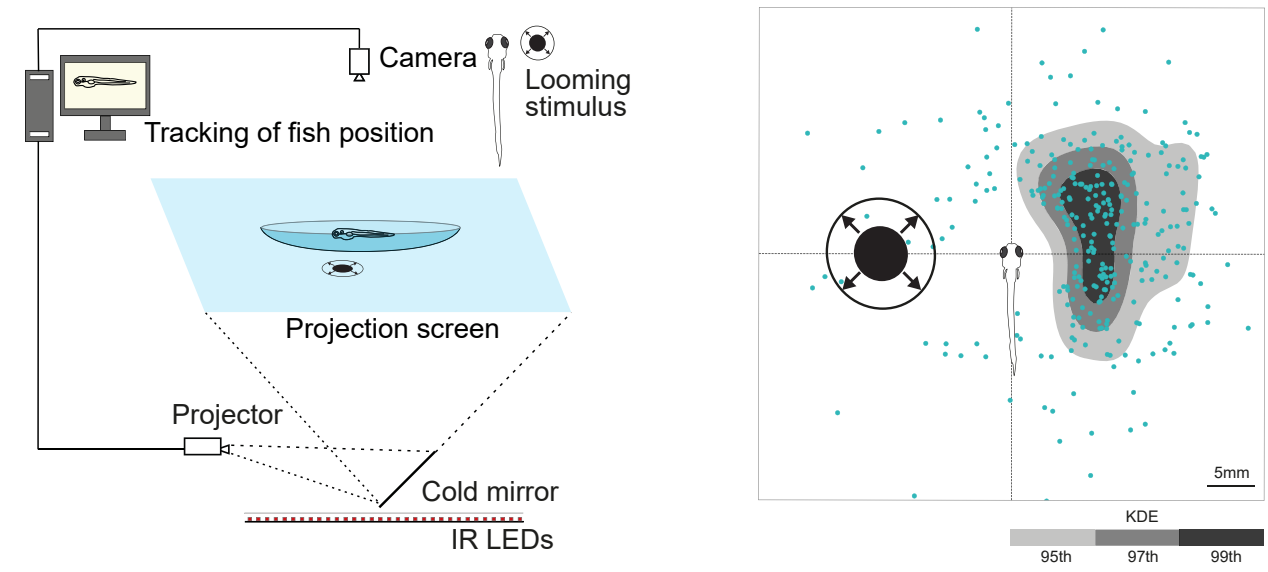

d

$\mathrm{S} 1=\mathrm{S} 2$

e

s2 alone (weaker)

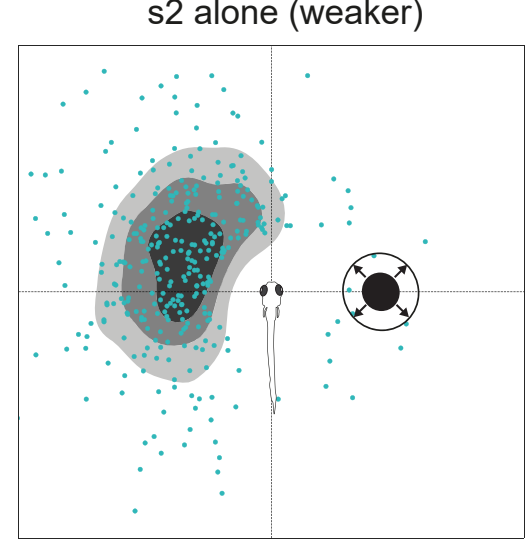

$\mathrm{f}$
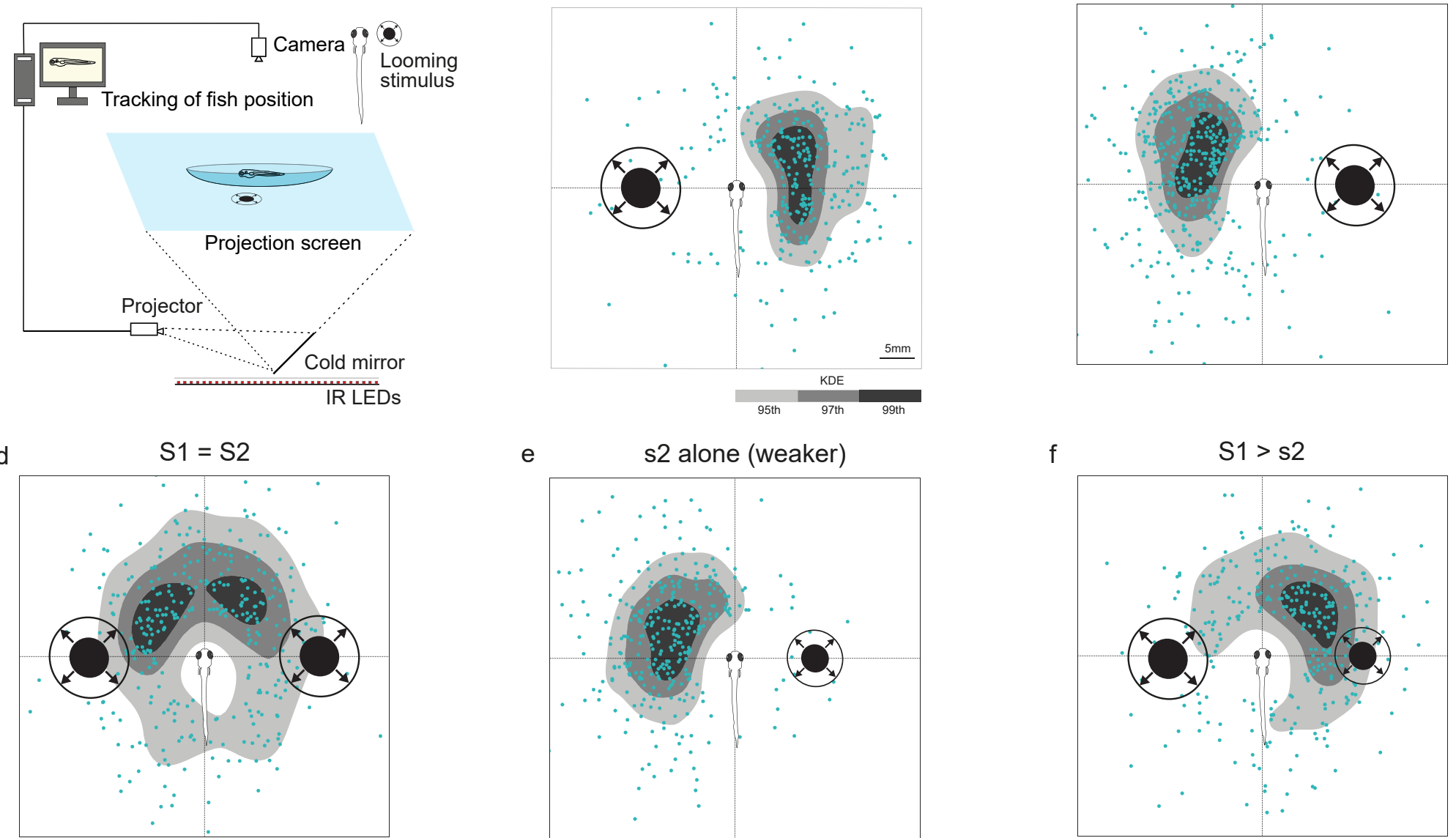

f

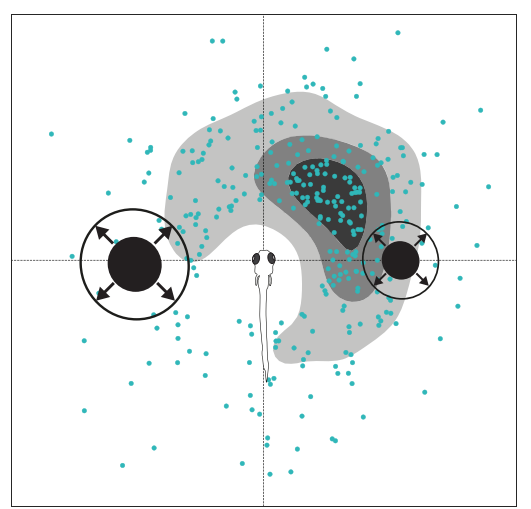

Modelling behavioural data
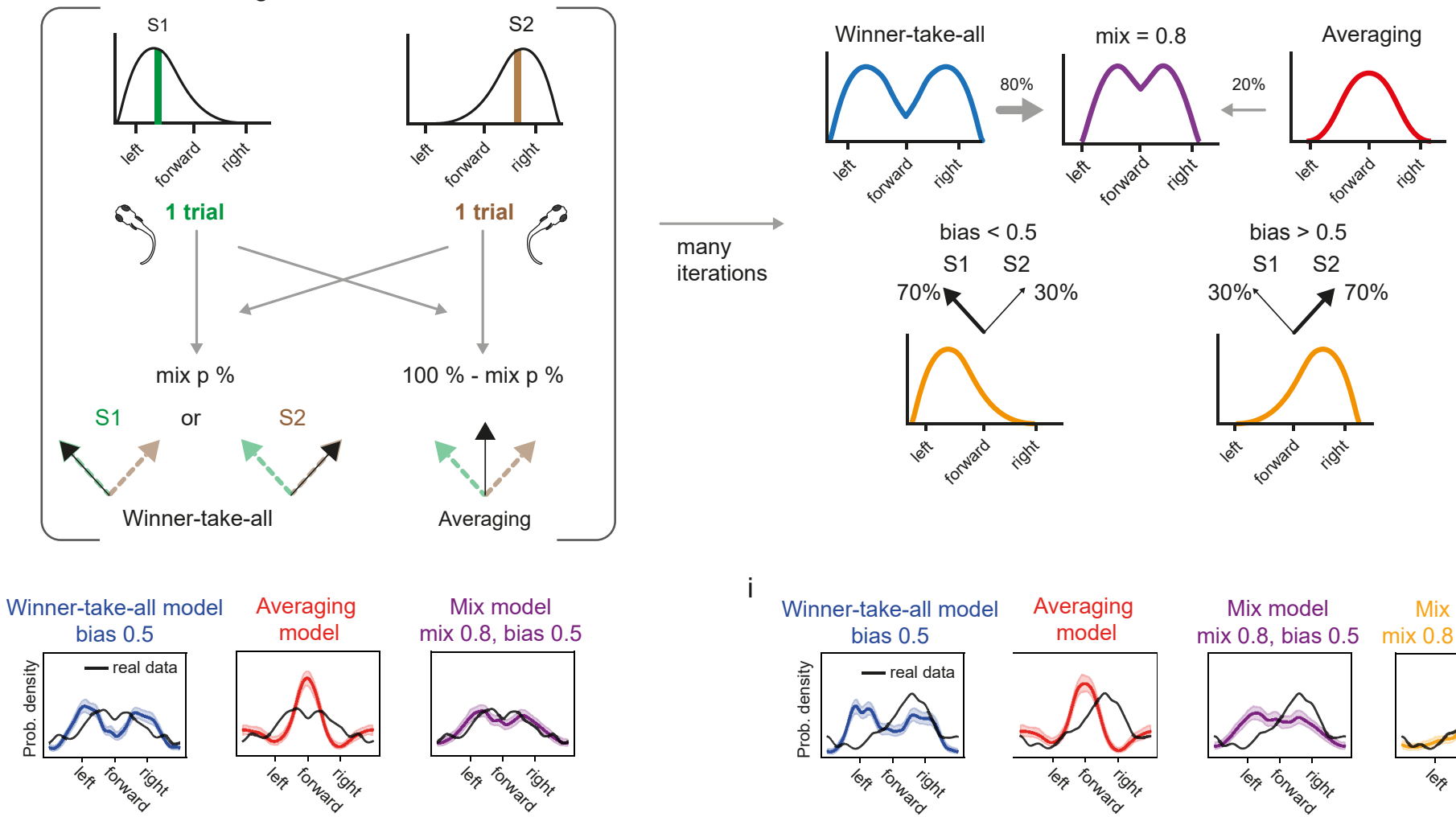

Mix model mix 0.8 , bias 0.5

i
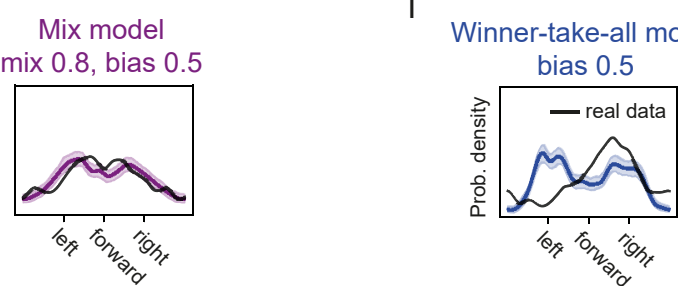

k

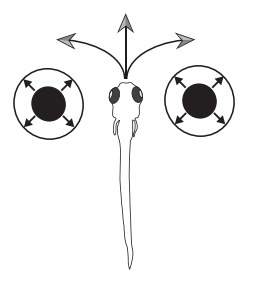

Mixed strategy Winner-take-all and Averaging

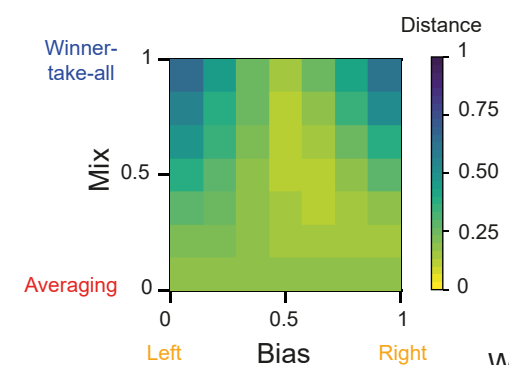

Bias
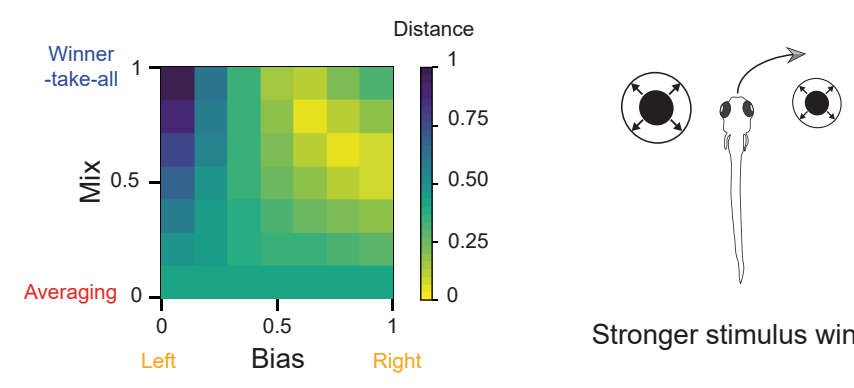

Stronger stimulus wins 
182 Figure 1. Zebrafish respond to competing stimuli according to their relative

183 saliencies.

184 a. Schematic drawing of the behavioural task used for measuring stimulus selection.

185 The animal is tracked while updating in real time the positions of the looming disks

186 projected from below. b. Response to a single looming stimulus (S1 alone, 90\%)

187 presented on the left side of the fish. Blue dots are the XY positions of the fish after

188 escape at the end of the expansion period of the stimulus (500ms). In grayscale are

189 the kernel density estimation (KDE) isocontours of the same data. c. Similar to (b), but

190 with stimulus presented on the right side of the fish. d. Competition (S1 + S2) of equal

191 stimuli $\left(90^{\circ} / \mathrm{s}\right)$. e. Weaker stimulus $(\mathrm{s} 2,60 \%$ s) on the right side of the fish. f. Competition

192 (S1 +s2) of unequal stimuli $(90 \%$ vs. 60\% $/ \mathrm{s})$. g. Modelling of the behavioural data,

193 which simulates the distribution of responses to competing stimuli by combing the

194 single trial responses to individual stimuli. One stimulus response from an S1 trial and

195 one stimulus response from an S2 trial are combined using repeated random sampling.

196 The winner-take-all model chooses randomly between the S1 response and the S2

197 response. The averaging model combines the pair of responses by taking the vector

198 average of the response angle. The mixture model implements a random assortment

199 between the winner-take-all model (with probability p) and the average model (with

200 probability 1-p). h. Modelling of behaviour outcome for equal stimuli competition.

201 Shaded areas are 97.5\% confidence intervals (CI). i. Modelling of behaviour outcome

202 for unequal stimuli competition. Shaded areas are $97.5 \%$ CI. j. Quality of the behaviour

203 reconstruction. Heatmap showing the normalised energy distance related to the panel

204 (g) depending on the model parameters (Bias and Mix). Bias: represents the probability 205 of response left vs right; Mix: represents the mixing factor between "winner-take-all"

206 and "averaging" models. k. Similar to j, but for unequal stimuli. N=117 fish. 
bioRxiv preprint doi: https://doi.org/10.1101/598383; this version posted April 4, 2019. The copyright holder for this preprint (which was not certified by peer review) is the author/funder, who has granted bioRxiv a license to display the preprint in perpetuity. It is made available under aCC-BY-NC-ND 4.0 International license.

a
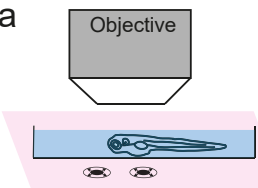

Projection screen

Projector

$\checkmark$ a Cold mirror

IR LEDs
Monocular competition

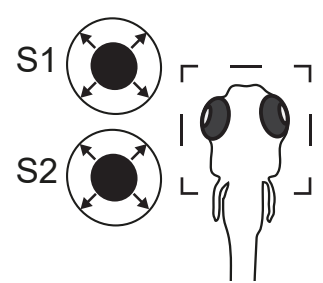

c

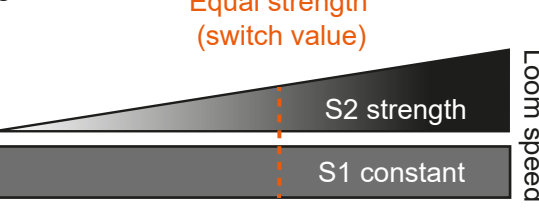

Predicted responses

S1 alone

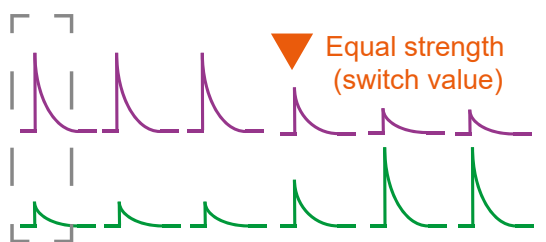

d

Tg(ath5:QF2); Tg(QUAS:GCaMP6s);Tg(elav/3:n/sGCaMP6s)

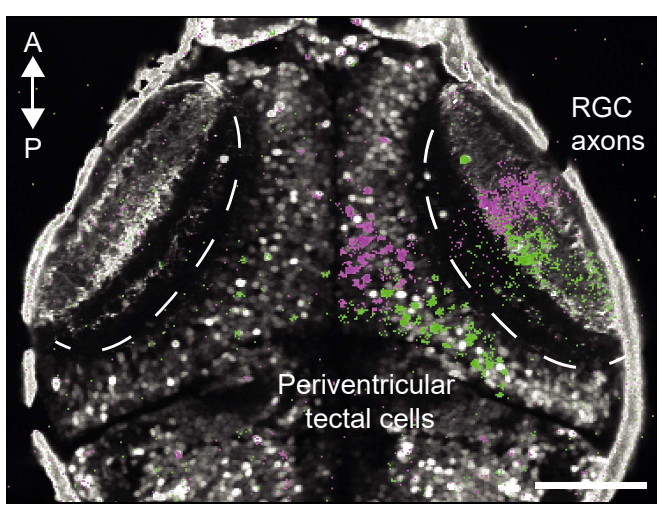

S1 responsive, suppressed by $\mathrm{S} 2$ $\mathrm{S} 2$ responsive e

$$
\begin{aligned}
& \text { S1 alone } \\
& \ulcorner-\neg
\end{aligned}
$$

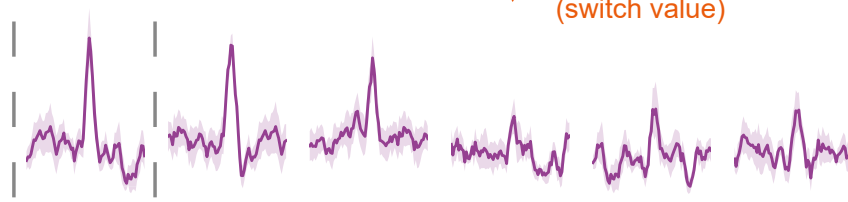

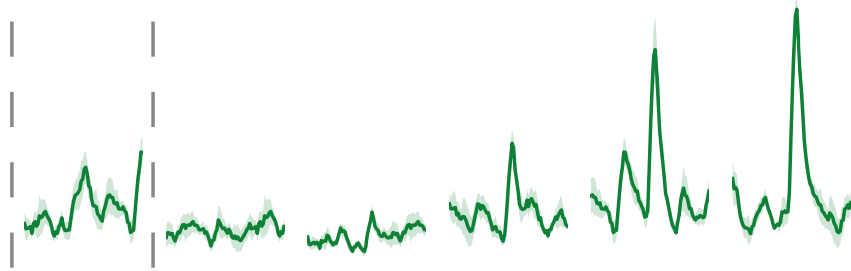$$
\text { ᄂ }-\perp
$$
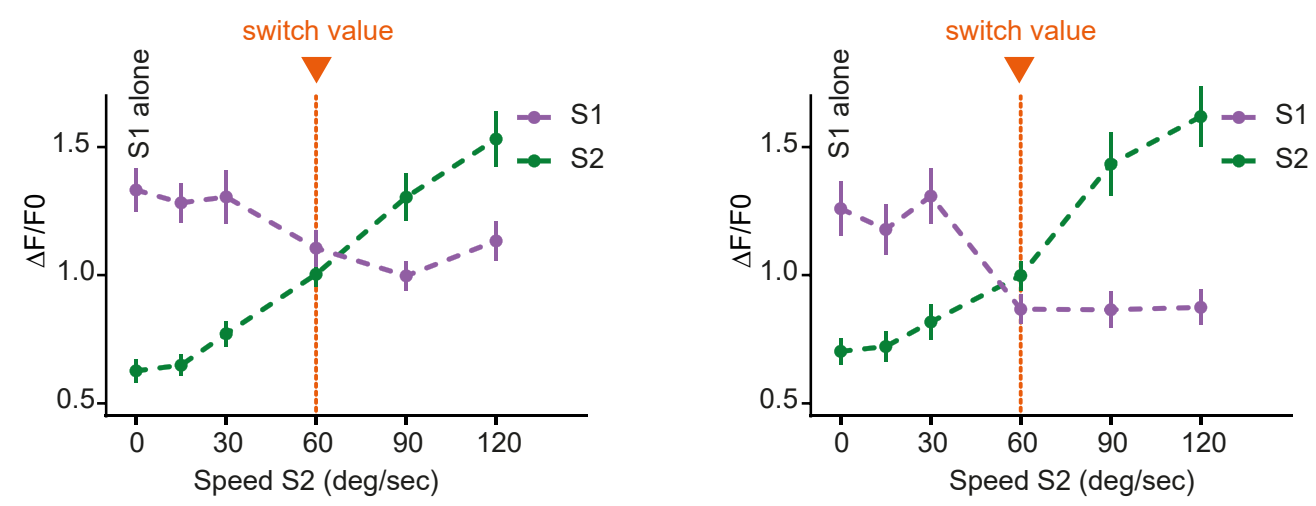

Tectal cells

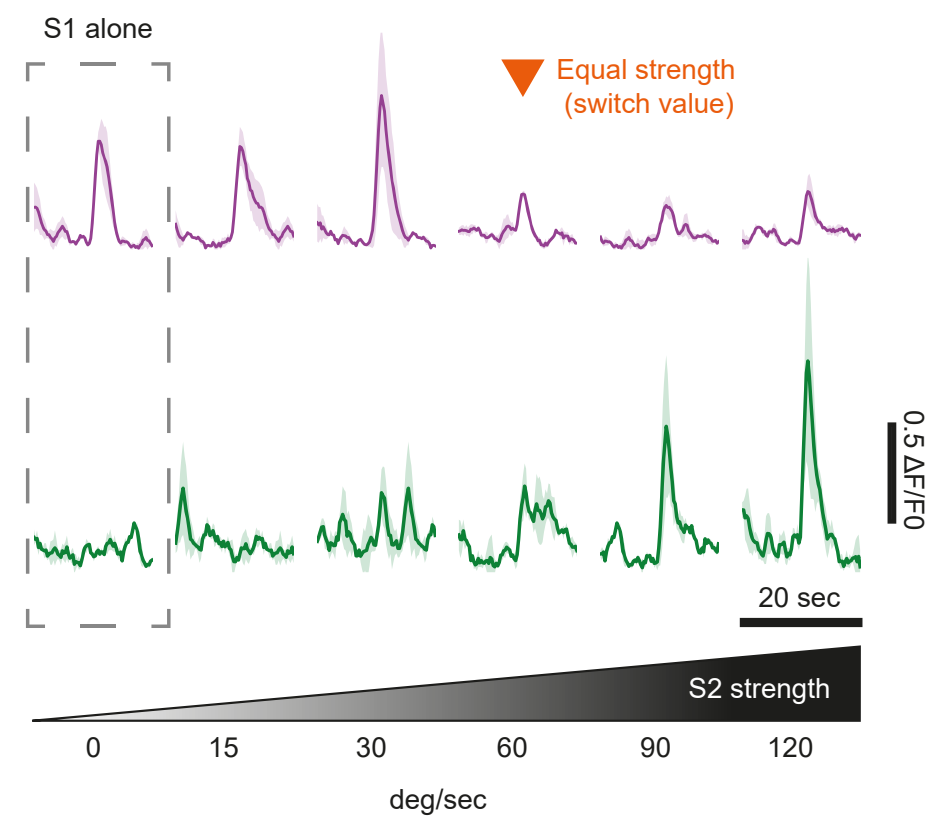

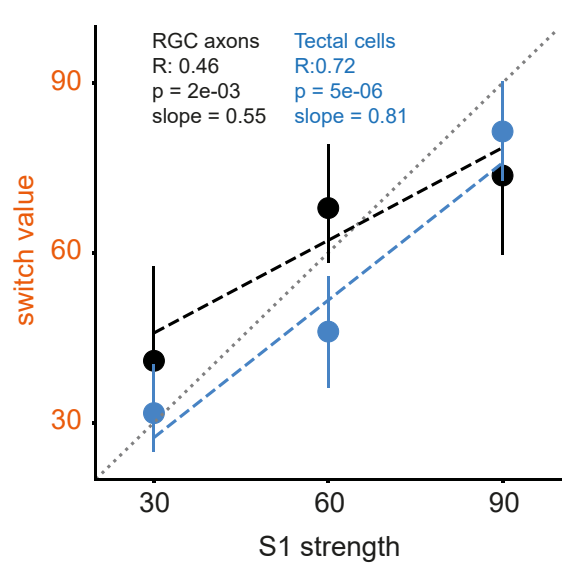


208 Figure 2. Retinal ganglion cell and tectal activity is suppressed during monocular 209 competition.

210 a. Left panel, schematic drawing of calcium imaging setup. Right panel, monocular 211 competition task. S1: stimulus 1, located in the anterior part of the visual field. S2: 212 stimulus 2, located in the posterior part of the visual field. b. Schematic of the 213 expression pattern of triple-transgenic fish used for this experiment (Tg(ath5:QF2; 214 QUAS:GCaMP6s; elav/3:n/sGCaMP6s)). Simultaneous recording of the activity of 215 RGC axons and tectal cells was carried out by combining an RGC-specific enhancer 216 (ath5:QF2), driving expression of cytoplasmic GCaMP6s (QUAS:GCaMP6s) (see 217 Extended Data Fig. 9), and a pan-neuronal enhancer, driving nuclear-localised 218 GCaMP6s (elav/3:n/sGCaMP6s). c. Schematic of competition protocol. Expansion rate 219 of one looming stimulus is kept constant (S1), while systematically varying the velocity 220 of the competitor stimulus (S2). In orange, condition where both stimuli have equal 221 strength ("switch value"). Below is shown the predicted responses types accounting for 222 stimulus selection d. Pixel-wise regression analysis of the temporal series during a 223 single imaging trial. Corresponding $t$-statistic for each pixel is calculated. Map shows 224 associated S1-responsive pixels, suppressed by a stronger S2 stimulus (in magenta), 225 and pixels that enhance their responses as a function of S2 strength (in green). Scale 226 bar represents $50 \mu \mathrm{m}$. e. Characteristic activity profiles for RGCs. Top traces, average 227 of 10 RGC axon ROls that were suppressed by a stronger S2 stimulus (in magenta). 228 Lower traces, average of 10 RGC axon ROIs that were enhanced by S2 (in green). $\mathbf{f}$. 229 Characteristic activity profiles for tectal periventricular neurons. Top traces, average of 23010 tectal ROIs that were suppressed by a stronger S2 stimulus (in magenta). Lower 231 traces, average of 10 tectal ROls that were enhanced by S2 (in green). S2 strength is 232 indicated below. Orange arrow shows condition where both stimuli have equal strength 233 ("switch value"). g. Summary plot across all conditions for RGC axon pixels. Switch234 like responses, showing RGC pixels suppressed by S2, are shown in magenta. RGC 235 pixels that were enhanced by $\mathbf{S} 2$ are shown in green. $\mathbf{h}$. Summary plot across all 236 conditions for tectal pixels. Switch-like responses, showing tectal pixels suppressed by 237 S2, are shown in magenta. Tectal pixels that were enhanced by S2 are shown in green.

238 i. Switch value increases with S1 strength for both RGC axons and tectal cells. R-value 239 is the correlation coefficient and the p-value relates to testing whether the slope is zero. $240 \mathrm{~N}=5$ fish. Errors are SEM. 
bioRxiv preprint doi: https://doi.org/10.1101/598383; this version posted April 4, 2019. The copyriaht holder for this oreprint (which was not

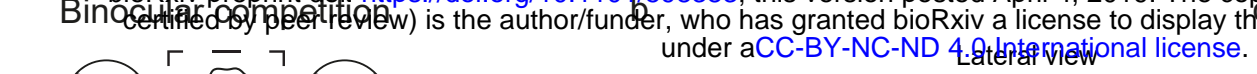
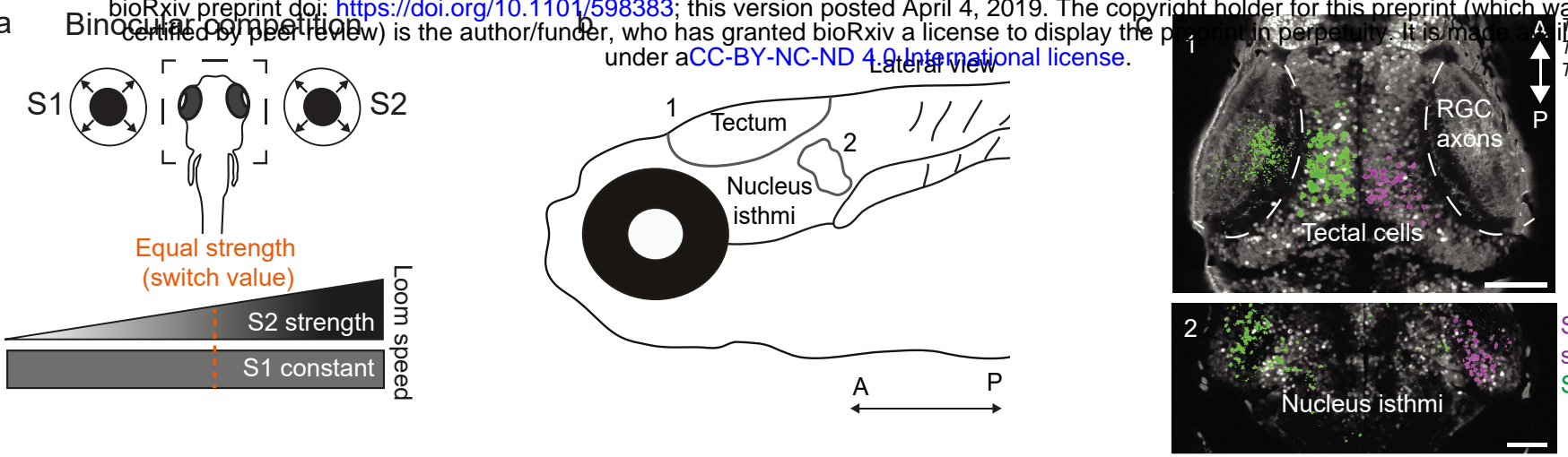

Ig(QUAS:GCaMP6s): g(elavl3:nlsGCaMP6s)

d S1 alone Tectal cells

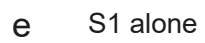

Nucleus isthmi

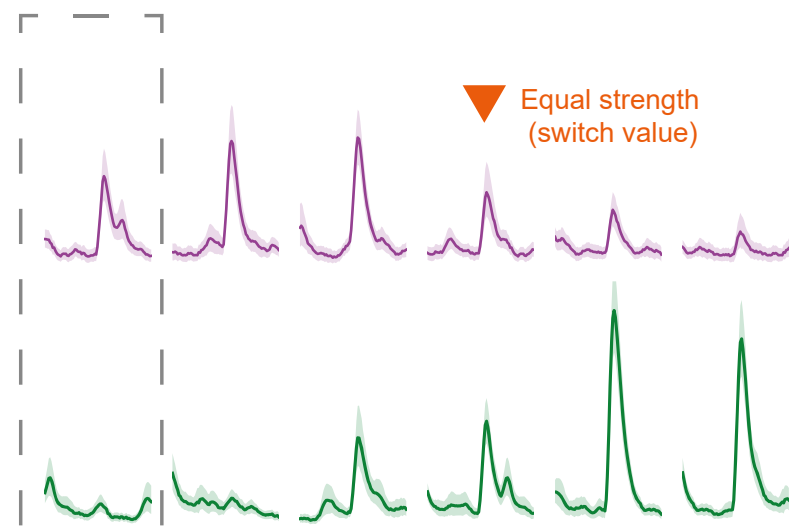

S2 strength

\begin{tabular}{llllll} 
& & & \multicolumn{2}{c}{ S2 strength } \\
\hline 0 & 15 & 30 & 60 & 90 & 120 \\
& & & & & \\
deg/sec & & &
\end{tabular}

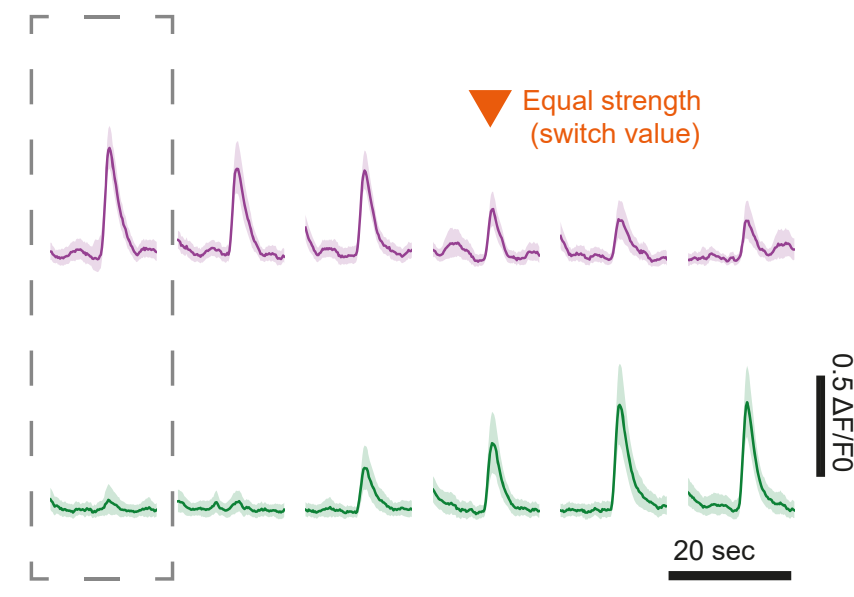

$\left\llcorner \_-\right.$

Nucleus isthmi

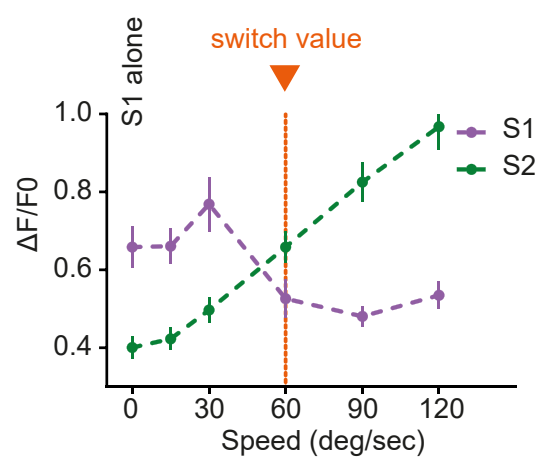

i
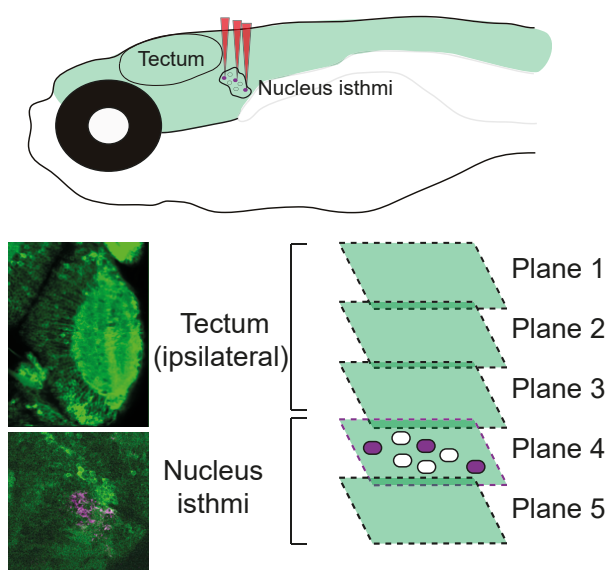

ChR2 in vglut2a nucleus isthmi cells GCaMP6s in all neurons

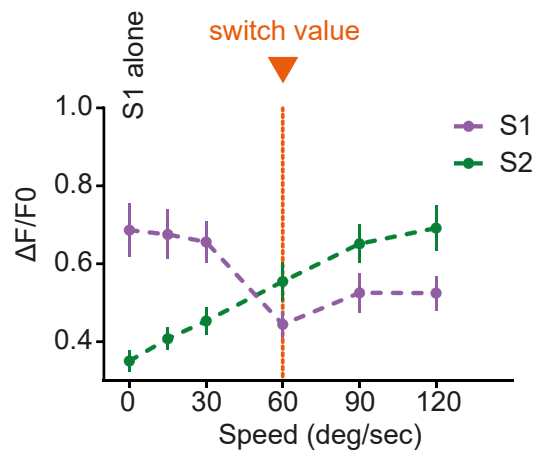

(8)

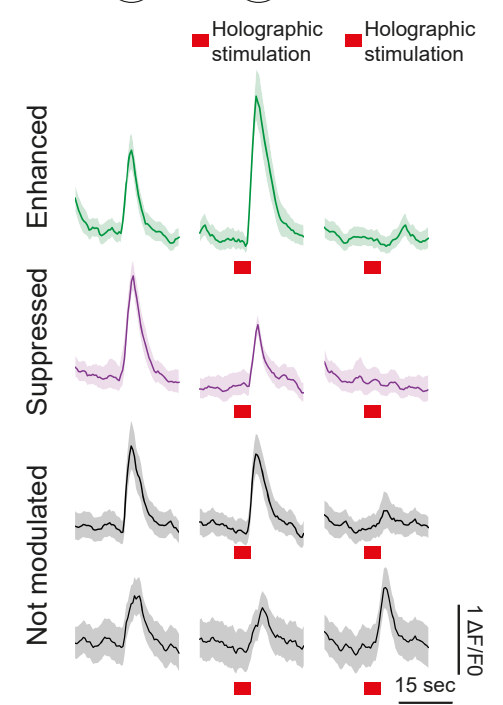

S2 strength

$\begin{array}{lllrrr}0 & 15 & 30 & 60 & 90 & 120 \\ & & \text { deg/sec } & & \end{array}$

h
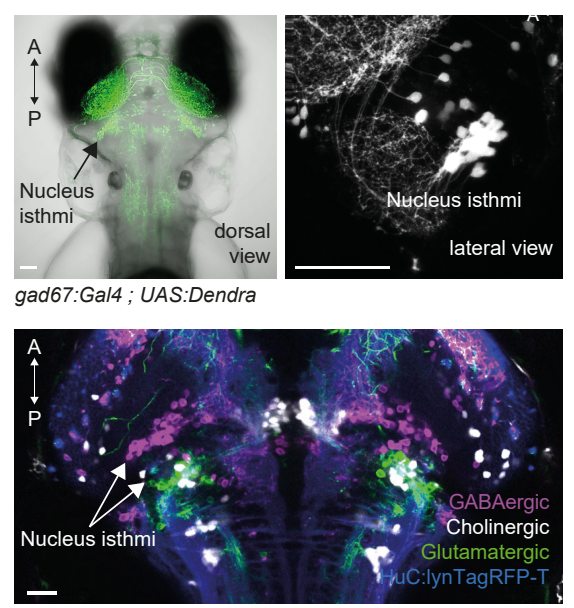

k

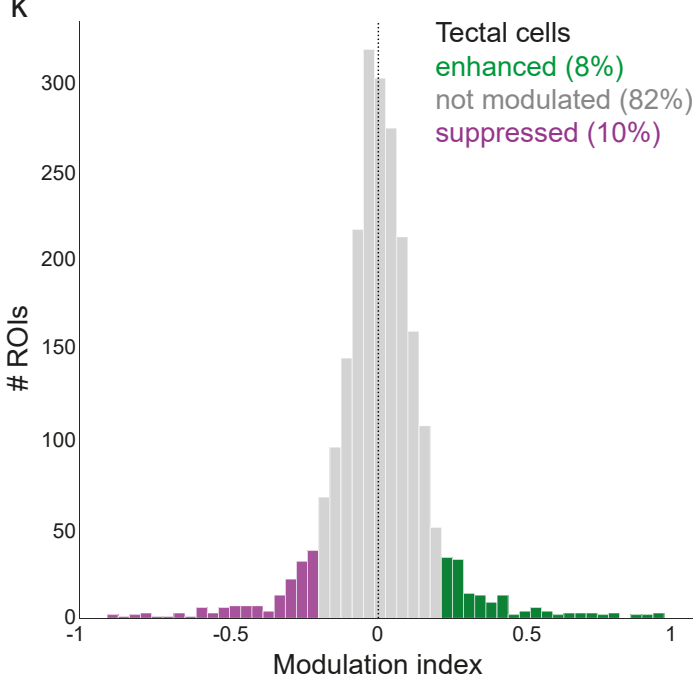


Figure 3. Winner-take-all dynamics in tectal and isthmic neurons in response to

242 competing binocular stimuli.

243 a. Binocular competition task. S1: stimulus 1, located on the left side of the fish. S2:

244 stimulus 2, located on the right side of the fish. In orange, condition where both stimuli 245 have equal strength ("switch value"). b. Anatomical location of the tectum and the 246 nucleus isthmi (NI) in zebrafish larvae. c. Pixel-wise regression analysis of the temporal 247 series during a single imaging trial. The $t$-statistic for each pixel is calculated. Map 1 248 shows associated S1-responsive tectal pixels, suppressed by a stronger S2 stimulus 249 (in magenta). Tectal pixels that enhance their response as a function of S2 intensity 250 are shown in green. Map 2 shows the same response profiles as in Map 1 but for the 251 nucleus isthmic. Scale bars represent $50 \mu \mathrm{m}$. d. Characteristic activity profiles for tectal 252 periventricular neurons. Top traces, average of 10 tectal ROls that were suppressed 253 by a stronger S2 stimulus (in magenta). Lower traces, average of 10 tectal ROls that 254 were enhanced by S2 (in green). e. Characteristic activity profiles for NI neurons. Top 255 traces, average of $10 \mathrm{NI}$ ROls that were suppressed by a stronger S2 stimulus (in 256 magenta). Lower traces, average of $10 \mathrm{NI}$ ROls that were enhanced by S2 (in green). 257 S2 strength is indicated below. Orange arrow shows the condition where both stimuli have equal strength ("switch value"). f. Summary plot across all conditions for tectal pixels. Switch-like responses, showing tectal pixels suppressed by $\mathrm{S} 2$, are shown in magenta. Tectal pixels that were enhanced by $\mathrm{S} 2$ are shown in green. $\mathrm{N}=5$ fish. $\mathbf{g}$. Summary plot across all conditions for NI pixels. Switch-like responses showing NI pixels that were suppressed by $\mathrm{S} 2$ are shown in magenta. $\mathrm{NI}$ pixels that were enhanced by $\mathrm{S} 2$ are shown in green. $\mathrm{N}=4$ fish. $\mathbf{h}$. Top left panel shows a dorsal image of a double-transgenic Tg(gad1b: Gal4VP16)mpn155; Tg(UAS:Dendra-kras)s1998t fish, labelling GABAergic neurons in green. Arrow indicates location of GABAergic NI neurons. Top right panel shows lateral view of Tg(gad1b: Gal4VP16)mpn155; Tg(UAS:nfsb-mCherry)c264 fish, labeling GABAergic neurons in white. Lower panel shows the alignment of transgenic lines used to label selectively the NI populations. Tg(gad1b: Gal4VP16)mpn155, labeling GABAergic NI neurons (magenta), Tg(Ihx9:

270 Gal4VP16)mpn203, labeling glutamatergic NI neurons (green) and 271 Tg(chata:Gal4VP16)mpn202, labeling cholinergic NI neurons (white). Tg(elavl3:lyn272 tagRFP)mpn404 is used as a reference channel (blue). Scale bars represent $50 \mu \mathrm{m}$. i. 273 Schematic of the experiment during two-photon computer-generated holography (2P$274 \mathrm{CGH}$ ) activation of specific excitatory isthmic neurons expressing channelrhodopsin 
275 (ChR2), combined with volumetric imaging of ipsilateral tectal responses. j. 276 Photostimulation of excitatory isthmic neurons modulates tectal responses during 277 visual stimulation (responses to looming). Some of the tectal cell responses are 278 unaffected by optogenetic stimulation (in grey), while others are either suppressed (in 279 magenta) or enhanced (in green). k. Histogram showing quantification of tectal 280 response modulation. Modulation index is defined as ((visual alone) - (visual combined 281 with optogenetic stimulation)) / ((visual alone) + (visual combined with optogenetic 282 stimulation)). $\mathrm{N}=4$ fish. 
bioRxiv preprint doi: https://doi.org/10.1101/598383; this version posted April 4, 2019. The copyright holder for this preprint (which was not certified by peer review) is the author/funder, who has granted bioRxiv a license to display the preprint in perpetuity. It is made available under aCC-BY-NC-ND 4.0 International license.
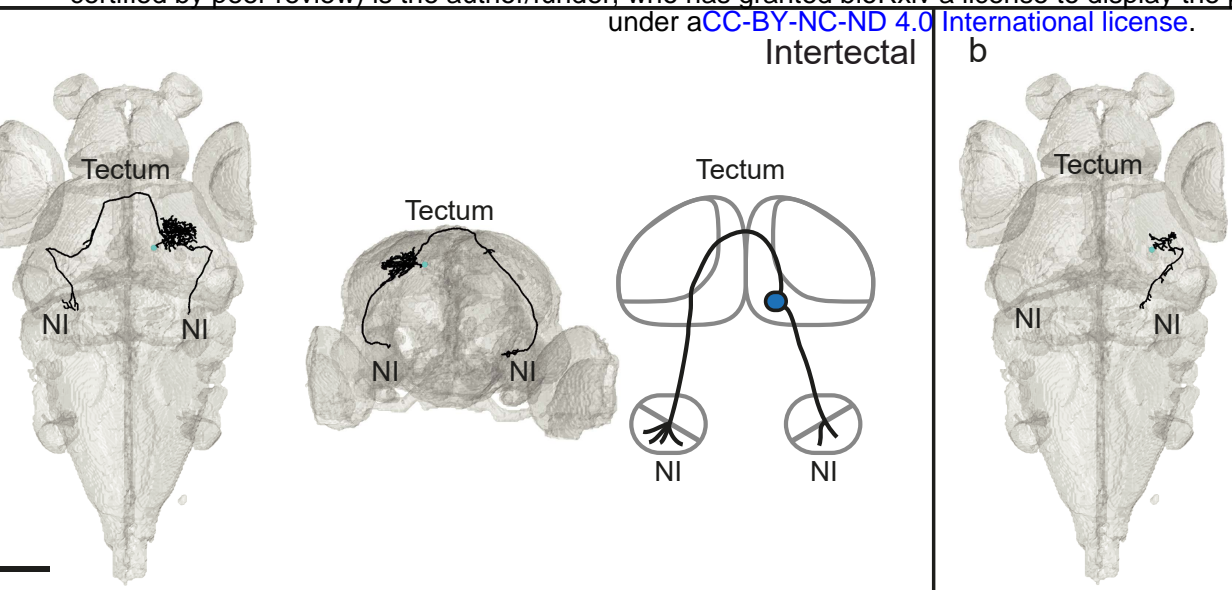

Ipsilateral tectobulbar

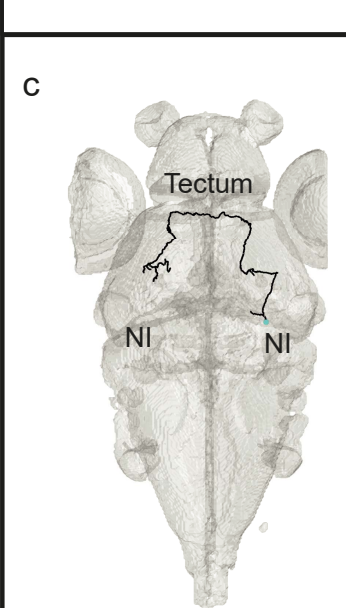

\section{Excitatory NI: ipsilateral-contralateral}

\section{d}

Excitatory NI: contralateral-ipsilateral

e

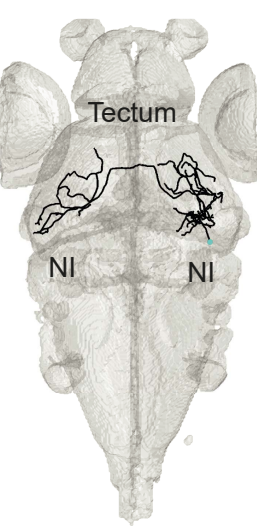

Inhibitory NI: ipsilateral-contralateral

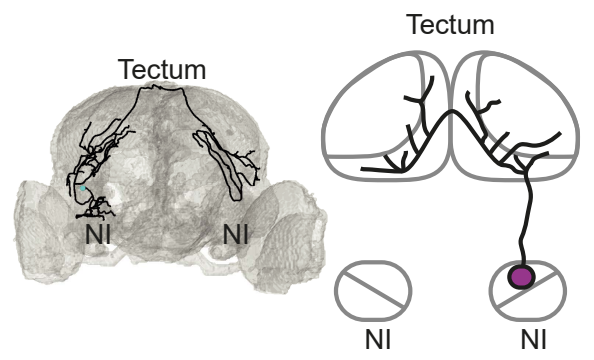

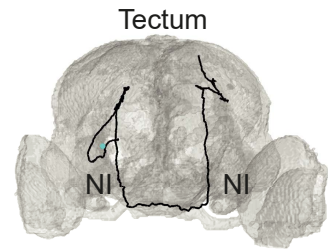

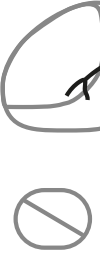

NI
Tectum

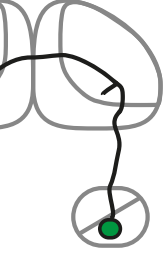

$\mathrm{NI}$
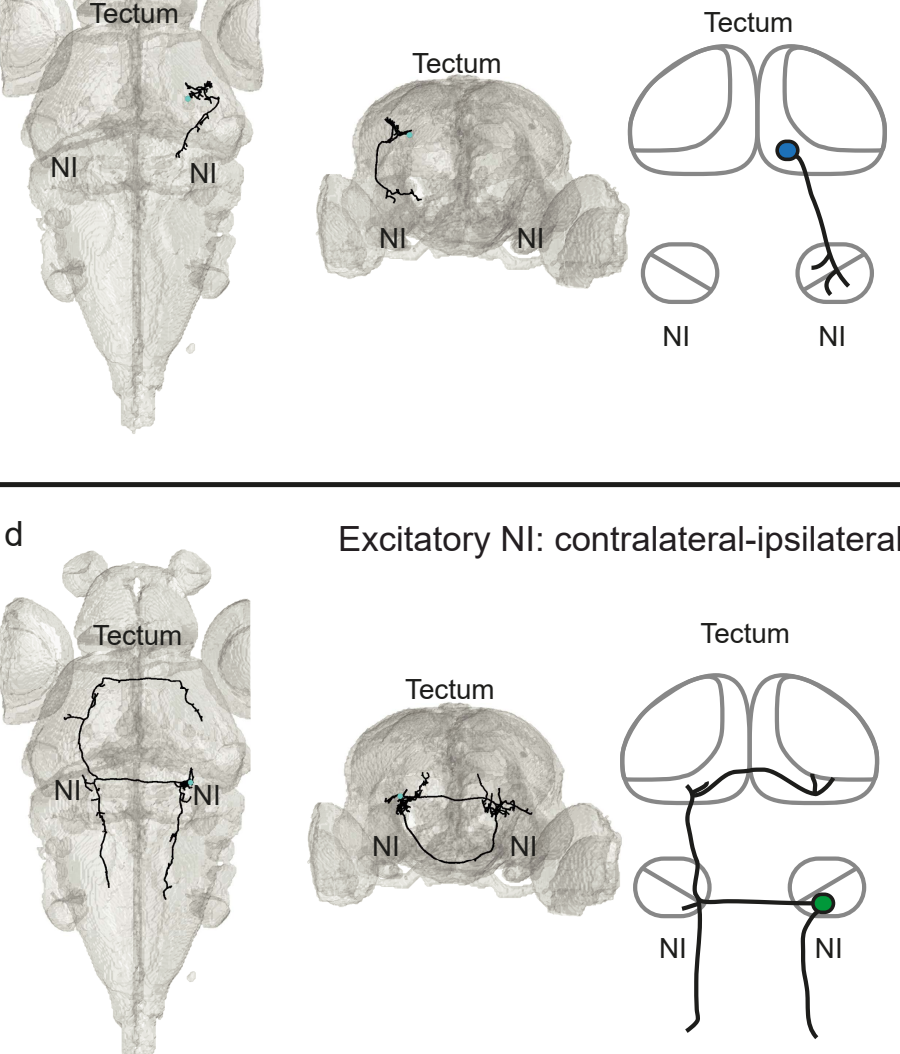

$\mathrm{NI}$

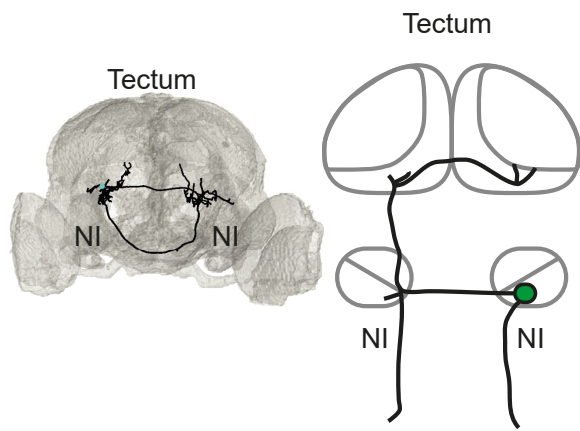

Inhibitory NI: ipsilateral

$f$

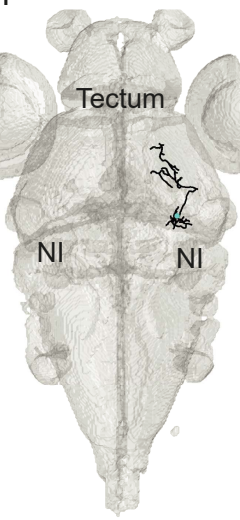

Binocular competition

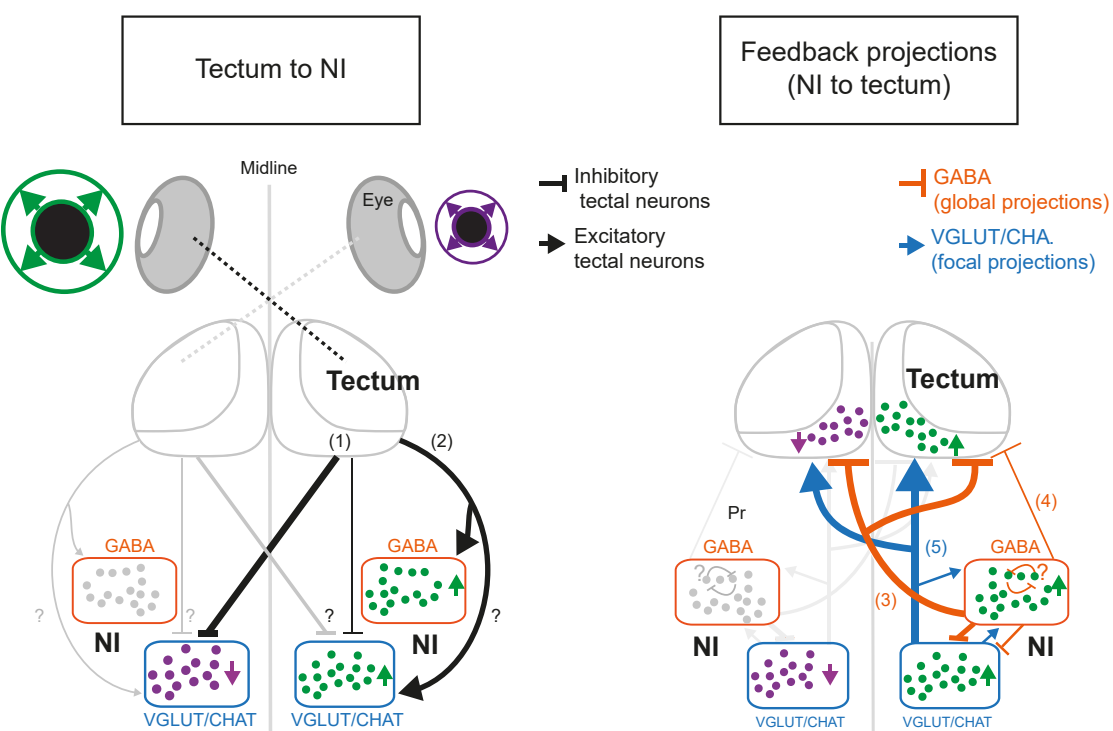


284 Figure 4. The isthmotectal loop is a possible substrate for binocular competition.

285 a-f. Single cell neuronal reconstructions (black traces). For each morphological type, 286 two views are shown (anterior-posterior and medial-lateral axis), plus a schematic of 287 isthmotectal circuitry (right). Scale bar represents $50 \mu \mathrm{m}$. g. Summary of findings. Left: 288 Hypothetical model for monocular competition. Amacrine cells (orange) inhibit each 289 other and suppress post-synaptic RGCs (magenta). RGCs that respond to the most 290 salient, "winning" stimulus, are highly active (green). The result of this competition is 291 conveyed to the tectum through RGC axons and further augmented by a tectum292 intrinsic circuit. Right: Anatomical connectivity of the isthmotectal loop and hypothetical 293 circuit model for binocular competition. Tectal cells are depicted in black. Putative 294 inhibitory intertectal cells form axon collaterals to (1) differentially inhibit excitatory NI 295 cells on the ipsilateral and contralateral side. Putative excitatory tectal projection 296 neurons (2) activate both inhibitory and excitatory $\mathrm{NI}$ neurons on the ipsilateral side. 297 Intertectal cells project mainly to the dendrites of excitatory NI cells (Extended Data 298 Fig. 8d). Ipsilateral tectal projection neurons terminate in the excitatory and inhibitory 299 neuropil of the ipsilateral NI (Extended Data Fig. 8b-c). Selection of most salient 300 stimulus is done across the hemispheres. "Winning" stimulus activates both 301 contralateral inhibitory and contralateral excitatory NI neurons (green). "Losing" the 302 competition leads to suppression of the excitatory NI population (magenta). Feedback 303 projections from the $\mathrm{NI}$ to the tectum are shown in orange (inhibitory) and blue 304 (excitatory). Reciprocal projections between the excitatory and inhibitory NI cells are 305 shown inside the NI box. GABAergic NI neurons project via a superficial commissure 306 and arborise broadly in the contralateral and ipsilateral tecta (3) or only the ipsilateral 307 tectum (4), where they may implement reciprocal inhibition across hemispheres. 308 Excitatory NI neurons cross the midline via the postoptic commissure, located deep in 309 the diencephalon. One class of cells form collaterals in both the ipsilateral and the 310 contralateral tectum (5) (see Extended Data Fig. 8k), where they enhance the winning 311 activity (green cells in the tectum). Suppressed tectal cells are shown in magenta. The 312 other class of excitatory NI cells projects first to the contralateral glutamatergic NI, with 313 arborisations close to the pretectum, thalamus and a neuropil region close to the 314 contralateral semicircular torus and tectum, and then returns to the ipsilateral side 315 s (Fig. 4d, Extended Data Fig. 8f, 8h and 8I). We posit that this delayed excitation may 316 balance the system, once the behavioural response is finished. The third class of 317 excitatory cells projects only to the ipsilateral thalamus (Extended Data Fig. 8e, m). 
318 Question marks highlight circuit components whose neurotransmitter identity or

319 connections are unknown. NI: Nucleus isthmi. See also Extended Data Fig. 8.

\section{Acknowledgements}

The authors thank Anna Krammer, Yunmin Wu, David Northmore, Aristides Arrenberg and Ruben Portugues for technical advice and critical feedback. Enrico Kühn, Styliani Koutsouli, Krasimir Slanchev and Irene Arnold-Ammer provided technical support. Vilim Štih and Andreas Kist shared scripts used in the analysis of imaging data. K. Kawakami provided the SAGFF(LF)81C zebrafish line. W. Driever provided the riboprobes for gad67 and trh. We thank Eva Laurell, Michael Kunst and Nouwar Mokayes for help with experiments and analysis of some of the cells used for the anatomical reconstruction data. We thank all members of the Baier lab for critical discussions and helpful comments. Funding was provided by the Max Planck Society and the DFG (SFB 870 "Assembly and Function of Neural Circuits" and Priority Programme SPP 1926 "Next Generation Optogenetics").

\section{Author Contributions}

A.M.F. and H.B. conceived the project. A.M.F. designed and performed experiments and analyzed the data. J.L. build the behavioural setup and performed some of the behavioural data analysis. T.O.H. wrote some of the analysis code for imaging experiments and anatomical reconstruction data. Y.K. generated new lines and expression data for Q-system genetic tools used in the paper. D.M. performed the experiments and analysis regarding prey capture data. J.C.D. performed the modelling analysis of behavioural data and wrote parts of the code used to analyze imaging data. M.D.M. performed some of the experiments and analysis regarding imaging and optogenetic results. A.M.F. and H.B. wrote the manuscript with the assistance of all authors. All authors discussed the data and the manuscript.

\section{Competing interests}

The authors declare no competing financial interests. 


\section{References}

1. Sareen, P., Wolf, R. \& Heisenberg, M. Attracting the attention of a fly. Proc. Natl. Acad. Sci. 108, 7230-7235 (2011).

2. Knudsen, E. I. Neural Circuits That Mediate Selective Attention: A Comparative Perspective. Trends Neurosci. 41, 789-805 (2018).

3. Sereno, M. I. Caudal Topographic Nucleus Isthmi and the Rostra1 Nontopographic Nucleus Isthmi in the Turtle, Pseudemys scriptu. 28

4. Krauzlis, R. J., Bollimunta, A., Arcizet, F. \& Wang, L. Attention as an effect not a cause. Trends Cogn. Sci. 18, 457-464 (2014).

5. Marín, G. et al. Oscillatory bursts in the optic tectum of birds represent re-entrant signals from the nucleus isthmi pars parvocellularis. J. Neurosci. Off. J. Soc. Neurosci. 25, 7081-7089 (2005).

6. Wang, Y., Luksch, H., Brecha, N. C. \& Karten, H. J. Columnar projections from the cholinergic nucleus isthmi to the optic tectum in chicks (Gallus gallus): a possible substrate for synchronizing tectal channels. J. Comp. Neurol. 494, 7-35 (2006).

7. Kardamakis, A. A., Saitoh, K. \& Grillner, S. Tectal microcircuit generating visual selection commands on gaze-controlling neurons. Proc. Natl. Acad. Sci. 112, E1956-E1965 (2015).

8. Mcllwain, J. T. Receptive fields of optic tract axons and lateral geniculate cells: peripheral extent and barbiturate sensitivity. J. Neurophysiol. 27, 1154-1173 (1964).

9. Passaglia, C. L., Enroth-Cugell, C. \& Troy, J. B. Effects of Remote Stimulation on the Mean Firing Rate of Cat Retinal Ganglion Cells. J. Neurosci. Off. J. Soc. Neurosci. 21, 5794-5803 (2001).

10. Temizer, I., Donovan, J. C., Baier, H. \& Semmelhack, J. L. A Visual Pathway for Looming-Evoked Escape in Larval Zebrafish. Curr. Biol. CB 25, 1823-1834 (2015). 
11. Dunn, T. W. et al. Neural Circuits Underlying Visually Evoked Escapes in Larval Zebrafish. Neuron 89, 613-628 (2016).

12. Fotowat, H. \& Gabbiani, F. Relationship between the phases of sensory and motor activity during a looming-evoked multistage escape behavior. J. Neurosci. Off. J. Soc. Neurosci. 27, 10047-10059 (2007).

13. Yilmaz, M. \& Meister, M. Rapid innate defensive responses of mice to looming visual stimuli. Curr. Biol. CB 23, 2011-2015 (2013).

14. Bhattacharyya, K., McLean, D. L. \& Maclver, M. A. Visual Threat Assessment and Reticulospinal Encoding of Calibrated Responses in Larval Zebrafish. Curr. Biol. 27, 2751-2762.e6 (2017).

15. Koch, C. \& Ullman, S. Shifts in selective visual attention: towards the underlying neural circuitry. Hum. Neurobiol. 4, 219-227 (1985).

16. Lee, D. K., Itti, L., Koch, C. \& Braun, J. Attention activates winner-take-all competition among visual filters. Nat. Neurosci. 2, 375-381 (1999).

17. Li, X. \& Basso, M. A. Competitive Stimulus Interactions within Single Response Fields of Superior Colliculus Neurons. J. Neurosci. 25, 11357-11373 (2005).

18. Vokoun, C. R., Huang, X., Jackson, M. B. \& Basso, M. A. Response Normalization in the Superficial Layers of the Superior Colliculus as a Possible Mechanism for Saccadic Averaging. J. Neurosci. 34, 7976-7987 (2014).

19. Heap, L. A. L., Vanwalleghem, G., Thompson, A. W., Favre-Bulle, I. A. \& Scott, E. K. Luminance Changes Drive Directional Startle through a Thalamic Pathway. Neuron 99, 293-301.e4 (2018).

20. Gallagher, S. P. \& Northmore, D. P. M. Responses of the teleostean nucleus isthmi to looming objects and other moving stimuli. Vis. Neurosci. 23, 209-219 (2006). 
21. Asadollahi, A., Mysore, S. P. \& Knudsen, E. I. Stimulus-driven competition in a cholinergic midbrain nucleus. Nat. Neurosci. 13, 889-895 (2010).

22. Mysore, S. P., Asadollahi, A. \& Knudsen, E. I. Signaling of the strongest stimulus in the owl optic tectum. J. Neurosci. Off. J. Soc. Neurosci. 31, 5186-5196 (2011).

23. Mysore, S. P. \& Knudsen, E. I. A shared inhibitory circuit for both exogenous and endogenous control of stimulus selection. Nat. Neurosci. 16, 473-478 (2013).

24. Romano, S. A. et al. Spontaneous neuronal network dynamics reveal circuit's functional adaptations for behavior. Neuron 85, 1070-1085 (2015).

25. Mysore, S. P. \& Knudsen, E. I. Reciprocal Inhibition of Inhibition: A Circuit Motif for Flexible Categorization in Stimulus Selection. Neuron 73, 193-205 (2012).

26. Koyama, M. \& Pujala, A. Mutual inhibition of lateral inhibition: a network motif for an elementary computation in the brain. Curr. Opin. Neurobiol. 49, 69-74 (2018).

27. Semmelhack, J. L. et al. A dedicated visual pathway for prey detection in larval zebrafish. eLife 3, (2014).

28. Passaglia, C. L., Freeman, D. K. \& Troy, J. B. Effects of Remote Stimulation on the Modulated Activity of Cat Retinal Ganglion Cells. J. Neurosci. 29, 2467-2476 (2009).

29. Deny, S. et al. Multiplexed computations in retinal ganglion cells of a single type. Nat. Commun. 8, 1964 (2017).

30. Henley, J. M., Lindstrom, J. M. \& Oswald, R. E. Acetylcholine receptor synthesis in retina and transport to optic tectum in goldfish. Science 232, 1627-1629 (1986).

31. Gahtan, E., Tanger, P. \& Baier, H. Visual Prey Capture in Larval Zebrafish Is Controlled by Identified Reticulospinal Neurons Downstream of the Tectum. J. Neurosci. 25, 9294-9303 (2005). 
32. Förster, D. et al. Genetic targeting and anatomical registration of neuronal populations in the zebrafish brain with a new set of BAC transgenic tools. Sci. Rep. 7, 1-11 (2017).

431 33. Volkmann, K., Chen, Y.-Y., Harris, M. P., Wullimann, M. F. \& Köster, R. W. The zebrafish cerebellar upper rhombic lip generates tegmental hindbrain nuclei by longdistance migration in an evolutionary conserved manner. J. Comp. Neurol. 518, 2794-2817 (2010).

34. Dudkin, E. A. \& Gruberg, E. R. Nucleus isthmi enhances calcium influx into optic nerve fiber terminals in Rana pipiens. Brain Res. 969, 44-52 (2003).

35. Helmbrecht, T. O., dal Maschio, M., Donovan, J. C., Koutsouli, S. \& Baier, H. 438 Topography of a Visuomotor Transformation. Neuron 100, 1429-1445.e4 (2018).

439 36. Northmore, D. P. Visual responses of nucleus isthmi in a teleost fish (Lepomis macrochirus). Vision Res. 31, 525-535 (1991).

441 37. Herman, J. P., Katz, L. N. \& Krauzlis, R. J. Midbrain activity can explain 442 perceptual decisions during an attention task. Nat. Neurosci. 21, 1651-1655 (2018).

443 38. Jovanic, T. et al. Competitive Disinhibition Mediates Behavioral Choice and 444 Sequences in Drosophila. Cell 167, 858-870.e19 (2016). 